\title{
Antioxidant Activity of Spirulina Powder in Male Rate with Adenine-Induced Chronic Renal Failure
}

\author{
Waleed Khaled Yonis ${ }^{1}$, Ayyed Hameed Hassan² \\ ${ }^{1}$ M.Sc. Student, ${ }^{2}$ Prof. Dr., College of Veterinary Medicine, University of Karbala, Karbala, Iraq
}

\begin{abstract}
The present study aimed evaluate the role of spirulina in reduction the ability of adenine induction renal failure and its complication in male rates. Twenty four adult male rats used in the present study and divided into four groups, first group consider as control group, the second group received adenine $(100 \mathrm{mg} / \mathrm{kg})$ intraperitoneal, while the third group receive mixed with feed and adenine $(100 \mathrm{mg} / \mathrm{kg})$ intraperitoneal combined with spirulina powder $(750 \mathrm{mg} / \mathrm{kg})$ and the fourth group receive just spirulina powder $(750$ $\mathrm{mg} / \mathrm{kg}$ ) also with feed, the result showed experiment blood was collected to assessment kidney function for (KIM-1, Ureaandcreatinine), lipid profile function test for (cholesterol, triglyceride, LDL and HDL). parameter of antioxidant concentration for (SOD,GSH,MAD and ON).in the present study when treated by adenine group that showed increases KIM, Urea and creatinine. the lipid profile results showed significance increase $(\mathrm{p} \leq 0.05)$ in Cholesterol,TG and LDL in the second group which administrated adenine while HDL was decreased in the same group. . the results showed significance $(p \leq 0.05)$ decrease in the GSH, SOD and increase in the MAD and No in the second group. Spirulina powder showed significance enhancement in the most of parameters which studied to return near to the control group.
\end{abstract}

Keywords: Spirulina, Antioxidant, adenine-induced chronic renal failure.

\section{Introduction}

Kidneys are efficient organs that represent the main control system to maintain homeostasis of the body. They are affected by various chemicals and drugs that may do effect the functions ${ }^{1}$.

Kidney disease is one of the reasons that lead to the reduction quality of individual life in now days ${ }^{2}$. The kidneys of human are mainly participatory in liquidation and concentrating various materials and chemical factors that may reach a rise concentration and turn into toxics ${ }^{3}$. Renal failure (RF) is considered pathologically deadly because of serious hormonal and metabolic disturbances. Whereas some models of animal renal failure are used to evaluate the pathogenic damage of organs pathogenesis ${ }^{4}$. Chronic renal failure (CRF)

\section{Corresponding Author:}

Waleed Khaled Yonis

M.Sc. Student, College of Veterinary Medicine, University of Karbala, Karbala, Iraq

e-mail: waleed.k@s.uokerbala.eda results from irreversible and progressive damage of wide numbers of functioning nephrons. Renal toxicities, glomerulonephritis, and diabetic nephropathy may promote oxidative conditions, increase susceptibility of acute renal failure. ${ }^{5}$ The free radicals one of causes that lead to kidney failure. Oxidative stress is known as a main pathological process in renal failure which activates various pro-inflammatory cytokines and growth factors, finally leads to glomerulosclerosis, tubule-interstitial fibrosis, tubular cells apoptosis and senescence, as well as deactivated cellular regenerative pathways 6 . Spirulina are indicated to filamentous free-floating microalgae with spiral characteristics of its filaments. It is officially called Arthrosporia sp powderspirulina have anti-oxidant properties and scavenge the free radicals' duo to that effect in hepatic and renal failure induced rats ${ }^{7}$.

\section{Material and Method}

Experimental Design: Using Healthy adult 24 male rats (11-12 weeks old, weighting initially 150-200 gm, divided equally and randomly in to four groups. 
The first group (control negative) animal of this group will receive normal saline orally and the second group (control positive) rats in this group will treated with spirulina $(750 \mathrm{mg} / \mathrm{kg})$ orally for 30 days and the third group animal of this group will gavage with adenine orally $(100 \mathrm{mg} / \mathrm{kg}$ ) for 30 days to induce renal failure and the fourth group animal of this group will co-administrated adenine $(100 \mathrm{mg} / \mathrm{kg})$ intraperitoneal and spirulina powder $(750 \mathrm{mg} / \mathrm{kg})$ orally for 30 days. After 30 days of experiment animals will anesthetized and blood will collect via cardiac puncture then after animal will sacrificed to isolate liver and kidney in order to measure.

\section{Parameter of study was:}

Kidney function measured of (KIM-1,Urea and creatinine) according to manufacture (south Korea).

Lipid profile measured of (Cholesterol, TG, LDL and HDL) according to Fasce, 1982.
Liver function parameter of (AST and ALT) is determined by using a special kit (SPECTRUM AST - kit, Egypt- IFUFCC22 andSPECTRUM ALT - kit, Egypt- IFUFCC25).

Antioxidant of parameter (MAD, GSH, SOD and NO) the (MAD) was done according to ${ }^{9}$, while parameter done $\mathrm{by}^{8}$, the parameter done according to ${ }^{10}$ and the (SOD) parameter. The procedure was done according to the instructions of the manufacture of ELIZA Kit -Elabscience biotechnology/china.

\section{Result and Discussion}

The data was statically analyses by using SPSS program by use one way ANOVA and differences between mean were compared with the least significant difference (LSD). ${ }^{11}$

Table (1): The Effect of spirulina powder on kidney and liver function Parameters in Male Rats with induced chronic renal failure means \pm SD

\begin{tabular}{|c|c|c|c|c|c|}
\hline Groups & KIM Mg/dL & UEAR Mg/dL & CEART Mg/dL & AST U/ml & ALT U/ml \\
\hline Control & $\mathrm{C} 116.04 \pm 1.998$ & $\mathrm{C} 21.33 \pm 0.881$ & $\mathrm{C} 0.26 \pm 0.043$ & C95.16 \pm 33.408 & $\mathrm{C} 45.50 \pm 2.77014$ \\
\hline Adenine & A395.27 \pm 18.78 & A71.16 \pm 4.26 & $\mathrm{~A} 3.49 \pm 0.20$ & $\mathrm{~A} 325.83 \pm 40.21$ & $\mathrm{~A} 102.83 \pm 13.961$ \\
\hline Spirulina and adenine & B175.86 $\pm 8,96$ & B $37.16 \pm 4.57$ & B1.81 \pm 0.20 & B145.16 \pm 51.077 & B $68.33 \pm 7.99$ \\
\hline Spirulina & C106.10 \pm 1.99 & $\mathrm{C} 26.50 \pm 4.20$ & B1.47 \pm 0.09376 & C94.16 \pm 46.70 & C54.16 \pm 5.47 \\
\hline LSD & 12.03 & 6.23 & 0.46 & 46.8 & 12.3 \\
\hline
\end{tabular}

$\mathrm{N}=6$ significant different between tow groups noted by letters $(\mathrm{P} \leq 0,05)$

A transmembrane protein with $90-\mathrm{kDa}$ molecular whight called Kidney Injury Molecule_ 1 KIM-1. is over expressed found in proximal tubules of in rat and has an important role in repair epithelial layer of renal tubule in rat kidney with ischemic injury ${ }^{12,13}$. KIM-1 considered a remarkable biomarker for acute renal tubular kidney damage ${ }^{14}$. The existing study accept with other previous studies $^{15-17}$. Aguiar et al.,(2015) ${ }^{18}$ who found rise of kim-1 concentration, in induction chronic renal failure in male rats, also ${ }^{19,20}$, who reported elevation KIM-1 in patients with CRF in humans by comparison with control groups On the other hand, co-administration of spirulina powder with adenine in the present study causes a significant enhancement of the renal function indicators. Our results in coordinate with that reported by Gargouri et al., $(2018)^{21}$ who found that spirulina protects neonate rat from leads-induced nephrotoxicity via its antioxidant properties. This enhancement in KIM, urea and creatinine Might be attributed to ability of phycocyanin (a biliproteins pigment found in spirulina components) to the accelerated regeneration of tubular malfunction that caused by adenine or due to a diuretic activity of the phycocyanin ${ }^{23}$. In addition, Abdel-Daim $(2014)^{22}$ reported that the presence potassium in alga which in turn possess a diuretic effect. beside, spirulina alga rich in flavonoids that can demonstrate the increase of diuresis because flavonoids cause polyuria $\mathrm{as}^{24}$. 
Table (2): The spirulina powder Effect on biomarker of lipid profile in Male Rats with induced chronic renal failure means $\pm \mathrm{SE}$.

\begin{tabular}{|c|c|c|c|c|}
\hline Groups $\quad$ Parameters & Chloe, (mg`/dL) & $\begin{array}{l}\text { Triglycerides,(trig) } \\
\text { (mg } / \mathrm{dL})\end{array}$ & $\begin{array}{l}\text { Low density, lipoprotein, } \\
\text { (LDL) `(mg/dl) }\end{array}$ & $\begin{array}{c}\text { High _density lipoprotein, } \\
\text { (HDL) (mg/dl) }\end{array}$ \\
\hline Control & D115.16 \pm 17.96 & $\mathrm{C} 46.36 \pm 3.59$ & $\mathrm{~B} 110.06 \pm 8.33$ & $\mathrm{~B} 31.16 \pm 2.023$ \\
\hline Adenine & A217.16 \pm 13.58 & $\mathrm{~A} 175.00 \pm 11.80$ & A198.16 \pm 10.06 & $\mathrm{C} 17.50 \pm 2.5$ \\
\hline Spirulina and adenine & $\mathrm{B} 171.66 \pm 14.63$ & $\mathrm{~A} 167.50 \pm 12.15$ & B107.50 \pm 6.91 & $\mathrm{BC} 23.09 \pm 2.89$ \\
\hline Spirulina & $\mathrm{C} 138.33 \pm 10.39$ & $\mathrm{~B} 73.83 \pm 4.96$ & $\mathrm{C} 68.00 \pm 5.30$ & $\mathrm{~A} 42.11 \pm 2.023$ \\
\hline LSD & 9.74 & 5.28 & 4.33 & 3.45 \\
\hline
\end{tabular}

$\mathrm{N}=6$ Significant different between two groups noted by letters $(\mathrm{P} \leq 0,05)$

Analysis of variance in the found study revealed significant increase in Cholesterol, TG and LDL level in the group of male rats injected intraperitoneally with adenine in comparison with control and other treated groups and our results in agreement with that reported by Ghelani et al., $(2019)^{25}$. Elevation of LDL in serum of rat with adenine induced chronic renal failure, may be resulted from the downregulation of LDL receptors in responses to chronic renal failure ${ }^{26}$

According total cholesterol increment in the present study could be occur as a result of the acceleration biosynthesis of cholesterol throughout the upregulation of enzyme called HMG-CoA reductase 28 other explanation to rise cholesterol levels is due to a relative decrease of elimination of cholesterol via liver due to down-regulation of enzyme called cholesterol $7 \alpha$-hydroxylase (CYP7A1) in animals undergoing chronic kidney disease ${ }^{30}$.

Elevation triglyceride in the blood of chronic kidney disease patients are most common among lipid abnormalities ${ }^{31-33}$. In addition, expression and activity of hepatic lipase protein is also reduced in rats with chronic kidney disease ${ }^{34}$. Treatment with spirulina along that showed decreases significantly in serum of LDL, Cholest and Trigly when comparative with group adenine. The HDL level significantly increase when comparative with group adenine in this study reported with other study(Bhat et al.,2020). The hypo-lipaemic ability of spirulina was also reported in mice with alloxan-induced diabetes represented by reduce triacylglycerol and LDL as well as increase in HDL levels ${ }^{37}$. The enhancement of lipid profile could be occurs secondarily to activation of AMP-activated protein kinase signaling pathway which lead to downregulates the gene expression that involved in synthesis of lipid such as 3-hydroxy-3-methyl glutaryl coenzyme A reductase, Sterol regulatory transcription element binding factor- $1 \mathrm{c}$, and acetyl CoA carboxylase 35. Moreover, spirulina has ability to change alter microbiota of gut to lowering effects of lipid via increase count. Studies have revealed an increase in abundance of Prevotella, which in turn increases metabolism of bile leading to reduce lipid levels in the blood. Formicates are another group of bacteria which have ability to reduce serum LDL concentrations, which improved with spirulina supplementation.

Table (3): The Effect of spirulina powder on Antioxidant Activity liver of Male Rats with induced chronic renal failure means \pm SD

\begin{tabular}{|c|c|c|c|c|}
\hline Groups $\quad$ Parameters & GSH Ng/ml & SOD Ng/ml & MAD $\mu \mathrm{M} / \mathbf{l}$ & No. $\mu \mathrm{M} / \mathbf{l}$ \\
\hline Control & A9.82 \pm 1.13 & $\mathrm{~A} 41.43 \pm 8.12$ & $\mathrm{C} 82.44 \pm 12.21$ & $\mathrm{C} 170.15 \pm 27.16$ \\
\hline Adenine & C6.27 \pm 1.08 & $\mathrm{C} 24.83 \pm 4.53$ & A118.61 \pm 18.13 & A195.27 \pm 11.92 \\
\hline Spirulina and adenine & B8.19 \pm 0.21 & B34.64 \pm 3.68 & $\mathrm{~B} 100.23 \pm 22.09$ & $\mathrm{~B} 181.42 \pm 13.12$ \\
\hline Spirulina & $\mathrm{A} 10.16 \pm 1.23$ & $\mathrm{~A} 38.90 \pm 4.51$ & $\mathrm{C} 79.86 \pm 19.65$ & $\mathrm{C} 171.83 \pm 10.21$ \\
\hline LSD & 1.21 & 4.11 & 13,74 & 9.18 \\
\hline
\end{tabular}


Superoxide dismutases (SOD) is actually the firs`t detoxifying enzymes in the cell and therefore the most effective antioxidants. It is considered as an The endogenous antioxidant enzyme is essential,which acts as First line part protection mechanism against reactive oxygen species $\operatorname{ROS}^{39-40}$.

Financial Disclosure: There is no financial disclosure.

Conflict of Interest: None to declare.

Ethical Clearance: All experimental protocols were approved under the College of veterinary Medicine and all experiments were carried out in accordance with approved guidelines.

\section{References}

1. Maliakel DM, Kagiya TV, Nair CK. Prevention of cisplatin induced nephrotoxicity by glucosides of ascorbic acid and alphatocopherol. Exp Toxicol Pathol. 2008; 60(6): 521-527.

2. Chertow GM, Burdick E, Honour M, Bonventre JV, Bates DW. Acute kidney injury, mortality, length of stay, and costs in hospitalized patients. J Am Soc Nephro. 2005.

3. Loh A, Cohen AH. drug- induced kidney diseasepathology and current concepts. Ann. Acad. Med. Singapore. 2009.

4. Bellomo R, Ronco C, Kellum J, Mehta R, Palevsky $\mathrm{P}$, The ADQI workgroup (2004).Acute renal failure - definition, outcome measures, animal models, fluid therapy and information technology needs: the Second International Consensus Conference of the Acute Dialysis Quality Initiative (ADQI) Group. Critical Care 2004.

5. Nasri N, Ardalan MR, Rafieian Kopaie M. Mechanistic impacts of medicinal plants in diabetic kidney disease. Iran J Public Health. 2014.

6. Dehghan Shahreza, F. Oxidative stress, free radicals, kidney disease and plant antioxidants. Immunopathol Persa.2017; 3(2): e11.

7. Gabr G, El-Sayed S, Hikal M. Antioxidant Activities of Phycocyanin: A Bioactive Compound from Spirulina platensis. Journal of Pharmaceutical Research International.2020; 73-85.

8. Al- Zamely OM, Al-Nimer MS, Muslish RK. Detection the level of peroxynitrite and related with antioxidant status in the serum of patient with acute myocardial infarction". Nat J Chem.2001; 4: 625637.

9. Muslih RK., Al-Nimer MS, Al-Zamely OM. The study level of malondialdehyde after activation with $\left(\mathrm{H} 2 \mathrm{o}_{2}\right.$ and $\left.\mathrm{CuSO} 4\right)$ and inhibitition of desferoxamine and molsidomine.2002.

10. Breddt D, Snyder S. Annu.Rev .Biochem .1994; 63:175-195.

11. Daniel WW.Biostatistic :a foundation for analysis in the health sciences.7th.John Wily. philadelphia.1999; (8).

12. Han WK, Bailly V, Abichandani R, Thadhani R, Bonventre J. Kidney Injury Molecule-1 (KIM-1): a novel biomarker for human renal proximal tubule injury. Kidney international.2002; 62(1): 237-244.

13. Huo W, ZhangK, Nie Z, Li Q, Jin F. Kidney injury molecule-1 (KIM-1): a novel kidney-specific injury molecule playing potential double-edged functions in kidney injury. Transplantation Reviews.2010; 24(3): 143-146.

14. Liangos O, Perianayagam MC. Urinary N-acetyl$\beta$-(D)glucosaminidase activity and kidney injury molecule-1 level are associated with adverse outcomes in acute renal failure. Journal of the American Society of Nephrology.2007; 18(3): 904912.

15. Imarah A. Protective effect of Eruca Sativa leaves oil extract against induced renal failure in rats according to certain physiological and histopathological criteria. A Thesis Submitted to the Council of the Faculty of Science University of Kufa.). Journal of Biological Chemistry.2017; 273(7): 4135-4142.]

16. Al Za'abi M, Al Busaidi M, Yasin J. Development of a new model for the induction of chronic kidney disease via intraperitoneal adenine administration, and the effect of treatment with gum acacia thereon. American journal of translational research.2015; 7(1): 28.

17. Alqatab A, Hassan A. Evaluation of some Coagulation Factors in Male rat with Induce Chronic Renal Failure (CRD). Research Journal of Pharmacy and Technology.2019; 12(4): 18711874.

18. Aguiar C, Naffah-de-Souza C, Castoldi A. Administration of $\alpha$-galactosylceramide improves adenine-induced.2015.

19. O'Seaghdha C, Hwang S, Larson M. Analysis of a 
urinary biomarker panel for incident kidney disease and clinical outcomes. Journal of the American Society of Nephrology.2013; 24(11): 1880-1888.

20. Driver T, Katz R, Ix J, Magnani J. Ameliorative effects of Spirulina platensis against lead-induced nephrotoxicity in newborn rats: Modulation of oxidative stress and histopathological changes. EXCLI journal. 2018; 17: 215-232.

21. Abdel-Daim MM. Pharmacodynamic interaction of Spirulina platensis with erythromycin in Egyptian Baladi bucks (Capra hircus). Small Rumin Res.2014; 120:234-42.

22. Farooq S, Asokan D, Kalaiselvi P, Sakthivel R. Prophylactic role of phycocyanin: a study of oxalate mediated renal cell injury. Chemico-biological interactions. 2004; 149(1): 1-7.

23. Yuliana ND, Khatib A, Link-Struensee AM, Ijzerman AP. Adenosine A1 receptor binding activity of methoxy flavonoids from Orthosiphonstamineus. Planta Med. 2009; 75:1326.

24. Ghelani H, Razmovski V, Chang D, Nammi, S. Chronic treatment of curcumin improves hepatic lipid metabolism and alleviates the renal damage in adenine-induced chronic kidney disease in SpragueDawley rats. BMC nephrology. 2019; 20(1): 431

25. Liang K, Vaziri ND. Down-regulation of hepatic lipase expression in experimental nephrotic syndrome. Kidney Int.1997;51(6):1933-7.

26. Liang $\mathrm{K}$, Kim $\mathrm{CH}$, Vaziri ND. HMG-CoA reductase inhibition reverses LCAT and LDL receptor deficiencies and improves HDL in rats with chronic renal failure. Am J Physiol Renal Physiol.2005;288(3):F539-44.

27. Vaziri ND, Liang K. Down-regulation of tissue lipoprotein lipase expression in experimental chronic renal failure. Kidney Int. 1996;50(6):192835.

28. Vaziri ND, Liang KH. Hepatic HMG-CoA reductase gene expression during the course of puromycininduced nephrosis. Kidney Int.1995;48(6):197985.
29. Pandak WM, Vlahcevic ZR, Heuman DM, Krieg RJ, Hanna JD, Chan JC. Post-transcriptional regulation of 3-hydroxy-3-methylglutaryl coenzyme a reductase and cholesterol $7 \alpha$-hydroxylase in rats with subtotal nephrectomy. Kidney Intl. 1994; 46:358-64.

30. Pahl MV, Oveisi F, Khamiseh G, Vaziri ND. Intestinal absorption and biliary secretion of cholesterol in rats with nephrotic syndrome. Nephrol Dial Transplant.1998;13(6):1446-51.

31. Vaziri ND, Moradi H. Mechanisms of dyslipidemia of chronic renal failure. Hemodial Int.2006;10(1):17.

32. Attman PO, Samuelsson O. Dyslipidemia of kidney disease. Curr Opin Lipidol.2009;20(4):293-9.

33. Kwan BC, Kronenberg F, Beddhu S, Cheung AK. Lipoprotein metabolism and lipid management in chronic kidney disease. J. Am. Soc. Nephrol.2007; 18(4):1246-61.

34. Jin K, Norris K, Vaziri ND. Dysregulation of hepatic fatty acid metabolism in chronic kidney disease. Nephrol Dial Transplant.2013;28(2):313-20.

35. DiNicolantonio JJ, Bhat AG. Effects of spirulinaon weight loss and blood lipids: a review. Open heart.2020; 7(1): e001003.

36. Rodríguez-Hernández A, Blé-Castillo JL, JuárezOropeza MA. Spirulina maxima prevents fatty liver formation in CD-1 male and female mice with experimental diabetes. Life Sci.2001; 69:1029-37.

37. Li T, Liu Y, Wan X, Huang Z, Liu B, Zhao, C. Regulatory efficacy of the polyunsaturated fatty acids from microalgae spirulina platensis on lipid metabolism and gut microbiota in high-fat diet rats. International journal of molecular sciences.2018; 19(10): 3075.

38. Fridovich I. Superoxide radical and superoxide dismutases. Annual review of biochemistry. 1995; 64(1): 97-112.

39. Dringen R, Pawlowski P, Hirrlinger J. Peroxide detoxification by brain cells. Journal of neuroscience research. 2005;79: 157-165. 